\title{
Principles and Economic Effects of Private and State Systems
}

\author{
by Eamonn Butler*
}

\section{Bundling of risks in state systems}

Different countries treat occupational accident and disability insurance in different ways. Some have no such protection at all. Others have schemes organized through employers or industries as a condition of employment law. Some have competing social funds which offer this sort of protection. Many, including the United Kingdom, have government-run national schemes.

Perhaps the most common thing in the developed economies is for occupational accident and disability insurance to be bundled up with lots of other lifetime risks - unemployment insurance, for example, and perhaps medical care, long-term care, maternity benefits and so on - into some comprehensive form of national or social insurance.

This bundling of different risks within a comprehensive state package has important consequences for how we must think about the future of occupational accident and disability protection.

Firstly, the rules governing how it works will depend very largely on the global policy which governments take to their social insurance programmes. A general change in the eligibility criteria or payment conditions for state benefits will probably affect this specific segment along with all the rest. So, the global thinking on social policy is very important to the future of this sector.

Secondly, it may prove to be hard to extract occupational accident and disability schemes from other social insurances and treat them in some innovative way. Many people will argue that it is simply right for the protection package to be comprehensive, so that nobody can fall out of the social-insurance net. And those who run the state system are unlikely to agree that any single segment of it should simply be taken out of their control and run in some other way.

Thirdly, the occupational accident and disability element of a state scheme is likely to be bundled up not only with other insurances, but with things that are not insurance at all things like saving for retirement and welfare transfers between rich and poor.

\footnotetext{
* Director of the Adam Smith Institute, London.
} 
Thus, the UK national insurance system does not distinguish between what goes into pensions, what goes into genuinely insurable risks, and what is used to provide welfare support. Each benefit has some element of all these motives in its design and operation. As a result, it is extraordinarily difficult to ease any of the insurables out of the state system. Each one is charged with income-redistribution effects as well as the insurance effects, so there are plenty of gainers raising their voices to object against its being moved to a proper insurance basis - however rational that policy may actually be.

\section{The global move to individual-based systems}

If the lesson of theory is that we cannot properly discuss these issues without being aware of the bigger picture of social insurance, welfare and pension provision, then the lesson of recent fact is that we must expect big change, and soon.

All round the world, people are coming to accept that their welfare state systems are bankrupt - perhaps morally as well as financially. A few years ago we dared not even challenge the workings of the welfare state. Now people all over the world are wondering whether it can survive, or whether it should. Welfare state reform is the big picture in the developed economies for the next decade or more.

And the direction of reform is clear.

Trying to re-balance the books by cutting benefits or tightening eligibility rules is no good. It simply produces outrage among a population that rightly sees itself as being cheated. As seen in France, that can turn violent.

Doing nothing, trying to shore up the system, or not doing enough to change it, is no good either. That simply puts off the day of reckoning. Hence the public debt of rich countries like Japan and even Germany is predicted to grow, by twice or three times, as the burden of their social insurance system gets heavier and heavier.

But moving to a personalized system works.

Chile has shown that with its 1981 reform of the state pension system into personalized accounts, privately managed. Chile has achieved enormous growth partly as a result of having this new savings capital to draw on for investment in its growing industries.

The UK has also privatized a part of its pension system - the income-related tier. People in the UK can take out private pension schemes run by their employers, or personal schemes offered by life insurance companies. The value of those schemes now totals $\$ 1000$ billion, more than the private pension savings of the rest of Europe put together.

Other countries are sold on funding and individuation. Although Singapore runs a state pension system, it is funded and the accounts are held in the name of the individual. The rate of return on savings is abysmal, largely because it is a monopolistic state system: but still people save willingly because they know that what they put in remains theirs and cannot be taken from them. And from Australia to Denmark, the funding idea is catching on.

Many of these schemes also make some provision for lifetime risks as well as retirement savings. Again, the public is more willing to accept change than it used to be. People no longer assume that state benefits will be there for them when they need them. Finance ministers' attempts to keep expenditures down by eroding benefit levels and tightening eligibility conditions has convinced more and more people that they should look to the private sector if they want real protection. 
In the UK, the take-up of private alternatives to state benefits has been enormous, and is predicted to grow yet further, especially in long-term care insurance which - now that people are living long enough to need it - is in very short supply from the government. Despite our deep love of the National Health Service, which our politicians tell us is the "envy of the world", about $15 \%$ of us now insure privately so we do not have to use it. School fees insurance is commonplace; and the growing numbers of the self-employed in particular are familiar with private accident and disability insurance.

Of course, it all remains expensive. There is no great incentive to insure privately when you are forced to contribute into a state insurance scheme anyway. You end up paying twice. But more and more we are extending tax concessions for those who do pay for themselves, recognizing that it helps the state service too if their demand can be channelled into private alternatives.

\section{The difference between tax and personal provision}

Advocates of government-run social insurance systems rarely see much difference between taxes and savings, or taxes and insurance premiums. But there is a world of difference, and the effect of that difference on economic performance is much more profound than most people understand.

In the UK right now, we are having a debate on the future of long-term care, and one think-tank has argued that we need a new state long-term care insurance system, with people being compelled to pay premiums out of their wages.

But these are not premiums. These are taxes. An individual worker sees absolutely no benefit for the extra stoppages out of his or her pay-cheque. That individual has no choice of who provides the cover, where the funds are invested, or what amounts can be drawn under what conditions. Worse, he or she knows that the whole scheme is going to be run by the politicians. Would you willingly trust your future to the politicians of ten, twenty, or thirty years hence?

Contrast that with, say, a private pension scheme such as workers have in Chile. There the individual has complete choice of provider, and can switch between one and another if they think rates or service levels will be better. They have accounts in their name, and can check how much money they have in that account every day. When they die, they have savings to pass on to their children.

The tax-funded route is a powerful disincentive against employment, which the savings and personal insurance route is not. Particularly since social insurance tends to be funded by a payroll tax. In the state system, the employee sees taxes being deducted and going into a black hole, along with lots of other taxes, to be spent by politicians on what they think will benefit themselves. Young people in particular think they will never see that cash again. Money that is earmarked for private saving or insurance, however, has a direct and personal benefit that is clear to the contributor.

\section{Financial losses of a state scheme}

In January 1996, Professor Martin Feldstein tried to estimate the disincentive effect of the tax-funded US pension system on the US labour market. In other words, to what extent would people be discouraged, taking a job, getting worse pay or worse conditions as a result of the payroll tax? 
He calculated that the payroll tax used to finance the pension in the US by raising distortions and disincentives in the labour market, imposes a drag on the economy of $1 \%$ of GDP in perpetuity.

But the burden of state social insurance does not stop there.

An even larger burden, Feldstein continued, comes from the very low implied rate of return on everyone's state pension contributions. People would be much better off if they could invest the same money in private markets.

Thirdly, the economic loss is compounded by the fact that the payroll tax eats into people's ability to save and invest elsewhere, the crowding-out effect on savings (which he reckoned was about 50 cents lost saving for every dollar extracted in taxation).

Adding all that up, we discover that, if the US moved to a funded system like that in Chile, the gains from improved labour-market incentives and the higher real returns on saving would be equivalent to adding $3 \%$ to GDP every year, in perpetuity.

Of course, at $3 \%$ growth, we would be twice as well off in only 24 years. And this is only the government pension system, not the other insurables that make up the US welfare state. That is the scale of how the state system is holding us back.

\section{Other effects of the state system}

There are other profound effects of state welfare systems whose economic effects are not so easy to measure.

The tax-funded system divides the population into to opposing groups: contributors and beneficiaries. The beneficiaries have nothing to lose by campaigning for more generous benefits; and the more beneficiaries there are, the louder their voice and the stronger the political pressure to expand benefits yet more.

On the other hand, the contributors see no personal benefit for the money they pay out, and take various steps (from simply not bothering to work more than they have to, through employing creative accountants and using tax-avoidance schemes too illegal (taxdodging) to keep down their liability.

The higher the tax rate is pushed in order to meet the rising welfare bill, the greater the evasion.

Pensions and insurables that are funded on an individual basis, however, motivate people very differently. Here, the perceived benefit is directly linked to the amount paid. People are much more willing to contribute because they can see the direct benefit link.

In the state system there is no inducement for people to moderate their demand for benefits, or even to try to avoid becoming dependent on benefits at all. Where, by contrast, people must rely on personal savings or insurance to see them through hard times, they will be far more careful to avoid that misfortune, and far more frugal in dealing with it.

Some politicians ask, quite sensibly, whether the state system actually subsidizes the very things it tries to eliminate. In the UK we have tried to ease the burden of single parenthood almost entirely by paying cash benefits to single mothers. Then we are surprised to find that we have the highest rate of teenage pregnancy in Europe, and the greatest incidence of single parenthood - over a million such families. 
If there are men in the lives of these million families, they are probably regarded as an unreliable nuisance by the women. There is no need for bonds of mutual support and dependence between persons if the state supplies it more easily. And our children pick up this dismal culture as easily as they pick up everything else. Then we wonder why so many of them too become dependent on state benefits, see no merit in self-improvement, have low self esteem and drift into crime and vandalism.

It is difficult to measure the economic cost of such dysfunctionality, but it must indeed be profound.

\section{Individual-based solutions}

Marx was right. The problem is not to understand this strange world, but to change it. There is no point in trying to add new elements on to our state social insurance or to tamper with it in the hope that it will suddenly improve. It will never work: it has just taken us fifty years to recognize its full effects, and they are dire. No, we must think of completely new solutions.

The only solution is to move to a system based on saving and insurance, where future benefits are linked directly to past contributions. Then we can direct the welfare principle to its true task of relieving poverty, without it corroding the attitudes of the entire population.

And more and more countries are thinking along just these lines. In the UK, my own Institute has been leading the debate, proposing a personal lifetime account mechanism what we call a Fortune Account - to replace the present national "insurance" system.

\section{The design of a Fortune Account}

The Fortune Account is a simple alternative to the social insurance system. It is a personal, funded, lifetime account which people save for when they are young, fit and employed, in order to provide for themselves when old, sick or unemployed.

The Fortune Account is designed to meet the basic retirement and lifetime needs of everyone, not to provide tax-free extras for the rich. It is for the millions, not the millionaires.

The Fortune Account comprises three elements:

- savings towards a basic pension, which can be used only after retirement;

- insurance for lifetime risks, such as long-term unemployment and incapacity;

- savings for short-term risks such as temporary unemployment.

Fortune Accounts will be offered competitively by a range of approved providers including insurance companies and banks. If people do not like the service or performance they get from one provider, they can move their Account to another.

A Fortune Account must be the holder's property. The money saved in it can be willed and inherited. Politicians cannot pilfer it, nor gain from fiddling the rules. No longer are people forced to retire at a standard age on a standard pension: provided only that they have saved enough to make them independent of the state, they can make those decisions themselves. 


\section{Security and investor confidence}

Of course, if people are to entrust their basic savings and insurance to some private system, it must be secure.

The corporate finances of the companies which manage these vehicles must be legally separate from the funds of their customers. Thus, if a management company were to fail or suffer a change in ownership, the pooled funds of investors would still be secure.

We should insist that funds not be invested in particularly risky investments, and that providers maintain a reasonable spread between gilts, equities, property, and overseas investments.

The best regulator is choice. Account holders should be able to switch, at least annually, between providers. The system must be deliberately kept simple in order to make comparisons easy. Customers must receive clear and regular statements on the value of their Account, and be able to check it at any time. Any administration charges must be explicit.

\section{Building up and using a Fortune Account}

Most people would have a simple choice: they could either stay with the state system, or open a Fortune Account.

If they chose the latter, then instead of paying taxes into the state scheme, they would pay a regular contribution into their Fortune Account, and watch it grow. The specified amount could be a percentage (say $10 \%$ ) of income or a standard premium for everyone.

Those newly entering the workforce, however, would be required to go into the new system. Thus, when the last of that generation retires, the "welfare state" retires with them.

People who leave the state system and take out a Fortune Account would expect some form of recognition for the tax contributions they have made over past years. To avoid the whole cost coming at once, this is best done through a "recognition bond", with the relevant amount being paid into their Fortune Account when they retire.

A spouse, partner, relative or friend can pay in to a person's Fortune Account. This will help non-working family members in particular, who at present accrue limited rights in the state system.

Income support and other strictly welfare functions would remain with the state. Instead of having to pay its own benefits to claimants directly, the state can achieve the same ends more easily by topping up the Fortune Accounts of needy individuals.

Indeed, welfare would be easier to target once the savings and insurance elements had been separated. Incentive too would be positive: the state would be encouraging and helping people to work and to save, not penalizing them when they do.

\section{Starting up the system}

The easiest way to start up a Fortune Account system would be to begin it solely as an alternative to the basic state pension. Already the UK has world-beating expertise in pension management. Once confidence has grown in the new system, we could add on a standard insurance package to create a fully comprehensive Fortune Account. 
If people are allowed to opt out of the state system, the Treasury will have less income with which to pay current and future state beneficiaries. But the size of this funding gap is overstated. As I have said, the disincentives of the present system distort the labour market and put a drag on economic growth. By contrast, a funded system encourages savings and provides an enormous pool of investment that can feed economic growth. According to Professor Feldstein's estimates, the transition to a Fortune Account system could easily be afforded within a single generation.

\section{Conclusion}

Let me conclude where I began, saying that it is no use to think of particular insurable benefits, such as occupational accident and disability insurance, in isolation from the other benefits that comprise the "welfare state". People these days are looking for much wider packages than this: and it makes sense to replace the failing state systems with comprehensive packages, rather than to try to unpick the state system a piece at a time.

The Fortune Account works because it offers, more efficiently, the same depth of protection against lifetime risks that the state promises today. It works because they do not have to think about the individual benefits in great detail, but can opt for a simple benefits package.

It works above all because it gives people a stake in their own future security and prosperity. In so doing it reverses the effect of those perverse incentives that have eaten down to the very core of our postwar welfare state. The whole pathology of welfare dependence is replaced by a culture of self-provision.

Serious reform of the welfare state requires us to review some cherished beliefs; but there is every sign that it is possible. To design a welfare system that really works may not be so difficult after all. 